\title{
Genes involved in strigolactone biosyntheses and their expression analyses in columnar apple and standard apple
}

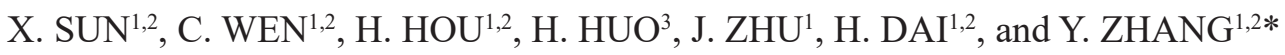 \\ College of Horticulture, Qingdao Agricultural University, Qingdao 266109, P.R. China ${ }^{1}$ \\ Qingdao Key Laboratory of Genetic Development and Breeding in Horticultural Plants, Qingdao Agricultural \\ University, Qingdao 266109, P.R. China ${ }^{2}$ \\ Mid-Florida Research and Education Center, University of Florida, Apopka, FL 32703, USA
}

\begin{abstract}
Columnar apple is a valuable resource for genetic improvement of cultivated apples due to its special tree architecture. Strigolactones (SLs) are a novel class of plant hormones controlling shoot branching. The content of SLs is higher in columnar apple than in standard apples. In this study, the members of major gene families involved in SLs biosynthesis and signaling were identified from apple genomic sequences and their expression profiles were characterized in columnar and standard apples using reverse transcription quantitative polymerase chain reactions. In comparison with standard apple, the higher expressions of MORE AXILLARY GROWTH genes MdMAX3-1 and MdMAX4-4 were detected in both buds and shoots of columnar apple but the expression of DWARF gene MdD53-4 showed a lower expression in columnar apple. Overexpression of Columnar gene MdCo31 in tobacco increased SLs content and weakened the inhibition of SLs signal transduction by increasing expression of MAX3 and down-regulating the transcription of D53. Thus MdCo31 could be a strong candidate gene for the control of columnar habit.
\end{abstract}

Additional key words: Columnar gene; Malus $\times$ domestica, Nicotiana tabacum, shoot branching, tobacco.

\section{Introduction}

The plant architecture is regulated by genetic factors, phytohormones, and environment factors as well. Phytohormones play a critical role in regulating shoot branching (Domagalska and Leyser 2011, Hollender and Dardick 2014). Several studies with branching mutants in some plant species have demonstrated that strigolactones (SLs) are the repressing hormone of long-shoot branching in both monocots and eudicots (Gomez-Roldan et al. 2008, Umehara et al. 2008, Zhou et al. 2013). Many naturally biosynthesized SLs have been identified and all share similar chemical structures, and are synthesized through the carotenoid cleavage pathway (Matusova et al. 2005, Kim et al. 2010, Yue et al. 2015). The SLs are categorized as apocarotenoids, and $\beta$-carotene is their substrate for synthesis (Al-Babili and Bouwmeester 2015).

Several studies have shown that DWARF3 (D3), D10, $D 14, D 17(H T D 1)$, and D27 in rice (Zou et al. 2006, Arite et al. 2007, 2009, Lin et al. 2009), MORE AXILLARY GROWTH 1 (MAX1), MAX2, MAX3 and MAX4 in Arabidopsis (Stirnberg et al. 2002, Sorefan et al. 2003, Booker et al. 2004), RAMOSUS 1 (RMS1), RMS4 and RMS5 in pea (Beveridge 2000), DECREASED APICAL DOMINANCE 1 (DAD1), DAD2 and DAD3 in petunia (Snowden et al. 2005, Hamiaus et al. 2012) are involved in either the biosynthesis or signaling of SLs (Zhou et al. 2013). Among these genes, MAX3/RMS5/D17/ DAD3, MAX4/ RMS1/D10/DAD1, MAX1 in Arabidopsis and $D 27$ in rice encode the carotenoid cleavage dioxygenase (CCD7), CCD8, CYP711A1 (a cytochrome $\left.\mathrm{P}_{450}\right)$ and a novel $\beta$-carotene isomerase, respectively, and they are involved in the sequential cleavage of $\beta$-carotene and synthesis of SLs (Alder et al. 2012). In contrast, $M A X 2 / R M S 4 / D 3$ and D14/DAD2, which encode an F-box protein and a protein of the $\alpha / \beta$-hydrolase superfamily, respectively, likely play a role in SLs signaling (Stirnberg et al. 2007, Arite et al. 2009, Hamiaux et al. 2012). The

Submitted 26 September 2018, last revision 17 January 2019, accepted 28 January 2019.

Abbreviations: CCD - carotenoid cleavage dioxygenase; Co - COLUMNAR; D - DWARF; EST - expressed sequence tags; MAX MORE AXILLARY GROWTH; RT-qPCR - reverse transcription quantitative PCR; SL - strigolactone; SPAD - chlorophyll content.

Acknowledgements: The authors are grateful to all the laboratory members for continuous technical advices and helpful discussions. This work was supported by the National Natural Science Foundation of China (Grant No. 31372032), the China Agriculture Research System Foundation (Grant No. CARS-27), and the Taishan Scholar Constructive Foundation and Qingdao Scientific Research Foundation (Grant No. 15-9-2-99-nsh). The first two authors contributed equally to this work.

* Corresponding author; e-mail: ygzhang@qau.edu.cn 
mutation of gene at stage of SLs biosynthesis could affect the whole synthesis process, and ultimately affect the regulation of the branching. MAX3 and MAX4 encode two enzymes know as CCD7 and CCD8. The mutants $\max 3$ and $\max 4$ have more branched phenotypes compared to wild-type (Arite et al. 2007, Drummoned et al. 2000, Steo et al. 2014). The MAX1 is required for the synthesis of active SLs. The enzyme activity of MAX1 was originally inferred from grafting experiments when maxl mutant rootstocks grafted to max 3 or max 4 mutant scions have wild-type levels of branching whereas reciprocal grafts are highly branched (Booker et al. 2005; Lazar et al. 2006). That result suggests the existence of a transmissible signal, which is downstream of the enzymes described above. The MAX3 and MAX4 could control the biosynthesis of the same graft-transmissible signal, but they have to act in the same tissue. On the other hand, $\max 1$ and $\max 3$ or $\max 4$ double mutant phenotype have no additional effect, indicating that maxl stock can produce a transmissible signal substance that is missing in $\max 3$ and $\max 4$ (Booker et al. 2005, Lazar et al. 2006). The results indicated that $M A X 1$ have actions in the downstream of MAX3 and $M A X 4$. The DAWARF53 (D53) was the first target protein of the D14-SCFMAX2 complex and its degradation led to the repression of lateral shoot growth (Zhou et al. 2013).

The columnar apple was initially discovered in 'Wijcik McIntosh', a sort of 'McIntosh' (Kesley and Brown 1992). This columnar habit is characterized by short internodes, reduced long branches, and increased lateral spurs on branches. The columnar habit could be attributed to the dominant allele of a single gene, Columnar ( $\mathrm{Co})$ (Petersen and Krost 2013, Hollender and Dardick 2014). To identify the Co gene and develop DNA markers for the columnar growth phenotype, apple genetic linkage maps have been constructed, which showed that the Co gene is located on linkage group 10 (Moriya et al. 2009). Several researches have reported the fine mapping of the $C o$ gene and mutations of the Co region (Bai et al. 2012, Moriya et al. 2012, Zhang et al. 2012, Baldi et al. 2013, Wolters et al. 2013, Otto et al. 2014, Petersen et al. 2015, Okada et al. 2016). Recent studies with comparing the genomic sequence of the Co region of columnar with standard apples have demonstrated that a DNA element/ Gypsy retrotransposon is inserted in an intergenic region of columnar apple (Wolters et al. 2013, Otto et al. 2014, Okada et al. 2016). Expression analysis of selected genes located in the vicinity of insertion revealed the upregulation of $M d C o 31$ gene, encoding a putative 2OG$\mathrm{Fe}(\mathrm{II})$ oxygenase or downy mildew resistant 6 (DMRO) (Wolters et al. 2013, Otto et al. 2014). Overexpression of MdCo31 in Arabidopsis thaliana and apples resulted in phenotypes with short internodes (Wolters et al. 2013, Otto et al. 2014, Okada et al. 2016). These results implied that $M d C o 31$ could be a strong candidate gene for the control of columnar habit.

In order to further study the relationship between SLs and columnar traits, 23 SLs biosynthesis and signaling related genes were identified in apple genome data following TBLASTN with amino acid sequences from Arabidopsis, pea, rice, and petunia based on previous reports. These genes included five $M d M A X 1$-related genes, one $M d M A X 2$, two $M d M A X 3$, three $M d M A X 4$, five $M d D 14$, three $M d D 27$, and four MdD53. The transcription patterns of twenty-three SLs biosynthesis and signaling related genes were detected using real-time PCR from different developmental buds and shoots of columnar and standard apple trees.

\section{Materials and methods}

Plants: The plant materials comprised four standard apples (Malus $\times$ domestica Borkh. cv. McIntosh, genotypes 21-S, 31-S, and 77-S) and four columnar apples (cv. Wijcik, genotypes 21-C, 31-C, and 77-C which were natural standard mutants of $21-\mathrm{C}, 31-\mathrm{C}, 77-\mathrm{C}$, respectively). Those trees were maintained in the Jiaozhou farm of Qingdao Agricultural University. Buds begin to germinate (0-d-old buds), 30-d-old buds, 60-d-old buds, as well as new shoots 30-d-old, 60-d-old, 90-d-old, and 120-d-old were collected from each sampling tree in the field and kept in ice box for about $1 \mathrm{~h}$ during transport, and then put into liquid nitrogen or ultralow temperature refrigerator.

Gene predication and expressed sequence tags (EST) analysis: Scaffold sequences of SLs biosynthesis/ signaling related genes in several species were identified from the none redundant gene list (http://www.rosaceae. org/node/58) of apple draft genome sequences through a TBLASTN search (ftp://ftp.ncbi.nlm.nih.gov/blast/ executables/blast+/LATEST/). Gene models were predicted from scaffold sequences using the GENSCAN web server (http://genes.mit.edu/GENSCAN. html).

The protein sequences of candidate genes in apple were used as queries to search the strigolactone biosynthesis related-EST sequences in each plant EST database (https:// www.ncbi.nlm.nih.gov/dbEST/index.html). The alignment parameters were: score $>100$ and E-value $>1 \times 10-20$. The tissue types of selected ESTs were isolated from the EST-GenBank format file, which was downloaded from NCBI dbEST. Target sequences were blasted back against Arabidopsis thaliana annotated sequences to obtain correct sequences.

Transcription profiling by reverse transcription quantitative PCR (RT-qPCR): Total RNA from each sample was prepared using a RNAprep pure plant kit according to the manufacturer's instructions (Tiangen Biotech, Beijing, China). First-strand cDNA was synthesized from $2 \mu \mathrm{g}$ of the total RNA using a HiScriptII 1st strand cDNA synthesis kit (Vazyme, Nanjing, China) and poly dT as a primer. The RT-qPCR was performed in three technical replicates for each of the three biological samples using a ChamQTM Universal SYBR qPCR master mix, $10 \mathrm{ng}$ of cDNA, and $0.2 \mu \mathrm{M}$ each primer according to the manufacturer's instructions (Vazyme). The MdActin, stably expressed in all of the tissues, was selected as a reference gene (Zhang et al. 2018). Relative expressions were calculated using the comparative $\mathrm{Ct}$ method with normalization of data to the geometric average of the 
reference gene expressions by the equation $2^{-\Delta \Delta \mathrm{Ct}}$. The primers used in RT-qPCR are summarized in Table 1 Suppl.

Strigolactone quantification: The SLs extraction and quantification by ultra performance liquid chromatography/mass spetrometry from buds were carried out as described by Zhou et al. (2013). Known amounts of deuterium-labeled standards for orobanchol, orobanchyl acetate, and fabacyl acetate (Zhou et al. 2013) were added before extraction, and endogenous hormone content was calculated from the ratio of endogenous to standard peak areas per gram of root fresh mass.

Vector construction for transformation of tobacco: For producing the $35 S-M d C o 31$, an EcoR I - Sac I fragment containing the $M d C o 31$ cDNA was cloned into the $p C A M B I A 1300$ binary vector, in which transgene expression was under the control of the CaMV $35 \mathrm{~S}$ promoter. The $p C A M B I A 1300-M d C o 31$ was used to transform tobacco. After the construct was transferred to Agrobacterium tumefaciens strain EHA105a by the freeze-thaw method, this A. tumefaciens was used to transform the leaves of five-leaf stage tobacco (Nicotiana tabacum L.) seedlings (Li et al. 2016). Putative transgenic plants (T0) were regenerated in the presence of $40 \mathrm{mg} \mathrm{dm}^{-3}$ hygromycin B and further screened by PCR. The seeds from T0 plants were sowed on hygromycin-containing medium for selecting T1 transgenic lines.

Chlorophyll meter reading: A chlorophyll meter (SPAD502, Minolta, Tokyo, Japan) was used to obtain leaf chlorophyll content (a SPAD value). Ten transgenic and wild-type plants were selected and SPAD values were recorded from the third (from top of the main stem) fully expanded leaf. Three SPAD value readings were taken per plants.

Statistical analysis: Values are shown as means \pm SEs of three independent experiments with three replicates each. Differences among samples were analyzed by one-way analysis of variance combined with the Duncan multiple range test.

\section{Results}

Recent studies demonstrated that MdCo31 is a strong candidate gene for columnar habit. In order to understand the relationship between the columnar type and the $M d C o 31$, the expression patterns of $M d C o 31$ were detected using real-time PCR from buds and shoots of different developmental stages of columnar and standard apples. The expression of $M d C o 31$ was significantly higher in the buds and shoots of columnar apple than that in those of standard apple (Fig. 1). The MdCo31 was generally more transcribed in buds compared to shoots in both standard and columnar apple trees.

Based on previous reports (Stirnberg et al. 2002, 2007, Arite et al. 2007; Gomez-Roldan et al. 2008, Umehara et al. 2008, Drummond et al. 2009, Kretzschmar et al. 2012, Waters et al. 2012, , Foo and Reid 2013, Jiang et al. 2013, Zhou et al. 2013), the strigolactones biosynthesis and signaling related genes were identified through a genome-wide strategy. Twenty-three SLs biosynthesis and signaling related genes were identified from apple genome data following TBLASTN with amino acid sequences from Arabidopsis, pea, rice, and petunia. These genes included five $M d M A X 1$-related genes, one $M d M A X 2$, two MdMAX3, three MdMAX4, five MdD14, three $M d D 27$, and four MdD53 (Table 2 Suppl., Fig. 2).

Strigolactones are widely recognized as shoot branching regulators. The SLs content was higher in columnar apple $\left(0.34 \mathrm{ng} \mathrm{g}^{-1}\right)$, whereas it was $0.11 \mathrm{ng} \mathrm{g}^{-1}$ in 'McIntosh'. To determine the expressions of all identified genes and if their expression patterns correlated with SLs biosynthesis, signaling, and the habit, expression analysis was employed in a set of buds and shoots of columnar and standard apple.

In this study, five $M d M A X$ genes were identified in apple and expressions of three of MdMAX1 (MdMAX1-1, MdMAX1-2 and MdMAX1-4) were confirmed in buds and shoots (Fig. 1 Suppl). The MdMAX1-1 expression in buds and shoots of columnar apple was higher than in standard apple. The expression of MdMAX1-4 was not detected in both columnar apple and standard apple. Only one MdMAX2 gene was identified in apple genome. The expression of $M d M A X 2$ in the shoots of columnar apple was higher than in standard apple, and there was no significant difference between columnar and standard apple in its expression in buds (Fig. 1 Suppl). Two MdMAX3 genes were identified. The expression of $M d M A X 3-1$ in columnar apple was higher than in standard apple, and the expression in standard apples except 21-S was exceptionally weak (Fig. 1 Suppl.). In the buds of columnar apple, the expression of $M d M A X 3-1$ started to increase and then decreased, and the expression in the shoot tips of columnar apple showed a downward trend. The transcription of MdMAX3-2 was nonspecific in the buds of columnar and standard apples (Fig. 1 Suppl.).

A total of five $D 14$ genes were identified. The expression of four MdD14 genes could be detected in columnar and standard apples. The MdD14-4 exhibited a down-regulated expression pattern in the buds whereas it demonstrated an up-regulated pattern in the shoots (Fig. 1 Suppl.). The transcript profiles of both MdD143 and MdD14-5 genes showed opposite trends (Fig. 1 Suppl.). The expression level of MdD14-1 was lower in early columnar apple buds and shoots than in those of standard apple, but the MdD14-5 expression of columnar apples was higher than that of standard apples (Fig. 1 Suppl.). The D27 might also be a key gene involved in the synthesis of SLs. The MdD27-1 expression was much lower in standard apple than in columnar apple. Buds had a comparable transcript abundance of $M d D 27-1$, but a lower expression in the shoot tips (Fig. 1 Suppl.). The D53 acted as a repressor of SL signaling. The SLs induced D53 degradation by the proteasome and abrogated its activity in promoting axillary bud growth. The expression of three members of MdD53 was detected. An MdD53- 
1 expression was highest in the buds and lowest in the shoot tips. The expressions of MdD53-4 were comparable between columnar and standard apples, but MdD53-1 and MdD53-3 had much higher transcript abundances in standard apple than in columnar apple. Interestingly, the MdD53-3 had comparable transcript levels in 'McIntosh' and 'Wijcik" (Fig. 1 Suppl.).

The MdCo31 was thought to be an important gene for regulation of columnar traits. In order to characterize the role of MdCo31 in SLs biosynthesis, signaling, and plant development, we chose to use the overexpression of $M d C o 31$ in tobacco plants. The MdCo31 transgenic plants were characterized by a decreased height and a significantly shorter internode length (Table 1, Fig. $3 A$ ). The leaves become thick and chlorophyll content increased (Table 1). Although there were no significant changes in the number of branches of transgenic plants, almost no long branch was observed in the transgenic plants (Fig. 3A). In order to investigate the function of $M d C o 31$ on the synthesis and signal transduction related genes of SLs, the expression of genes related to SLs biosynthesis and signaling in transgenic tobacco plants were studied (Fig. $3 C$ ). The results show that $N b M A X 3$ transcription was upregulated in transgenic tobacco, and $N b D 53$ was down-regulated. The expression of $N b M A X 1$ decreased in transgenic lines 8 and 9 , but increased in transgenic line 10. There was no significant difference in the expression of other genes between transgenic and wild tobaccos.

\section{Discussion}

The columnar apple is characterized by short internodes, reduced lateral branches, and increased spurs (Kelsy and

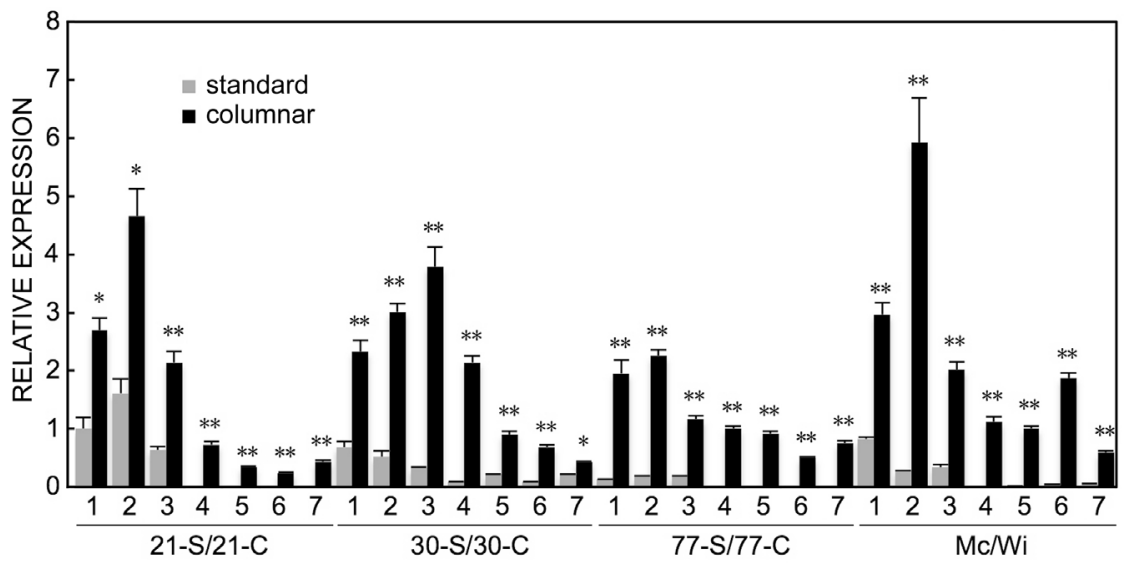

Fig. 1. The expression of $M d C o 31$ in standard (S) and columnar (C) apple genotypes 21, 31, and 77. 1,2,3,4,5,6,7 indicate 0-d-old buds, 30-d-old buds, 60-d-old buds, 30-d-old shoots, 60-d-old shoots, 90-d-old shoots, and 120-d-old shoots. Means \pm SEs, $n=3$, *and ** - significant differences at $P<0.01$ and $<0.001$, respectively according to the Duncan's multiple range test.

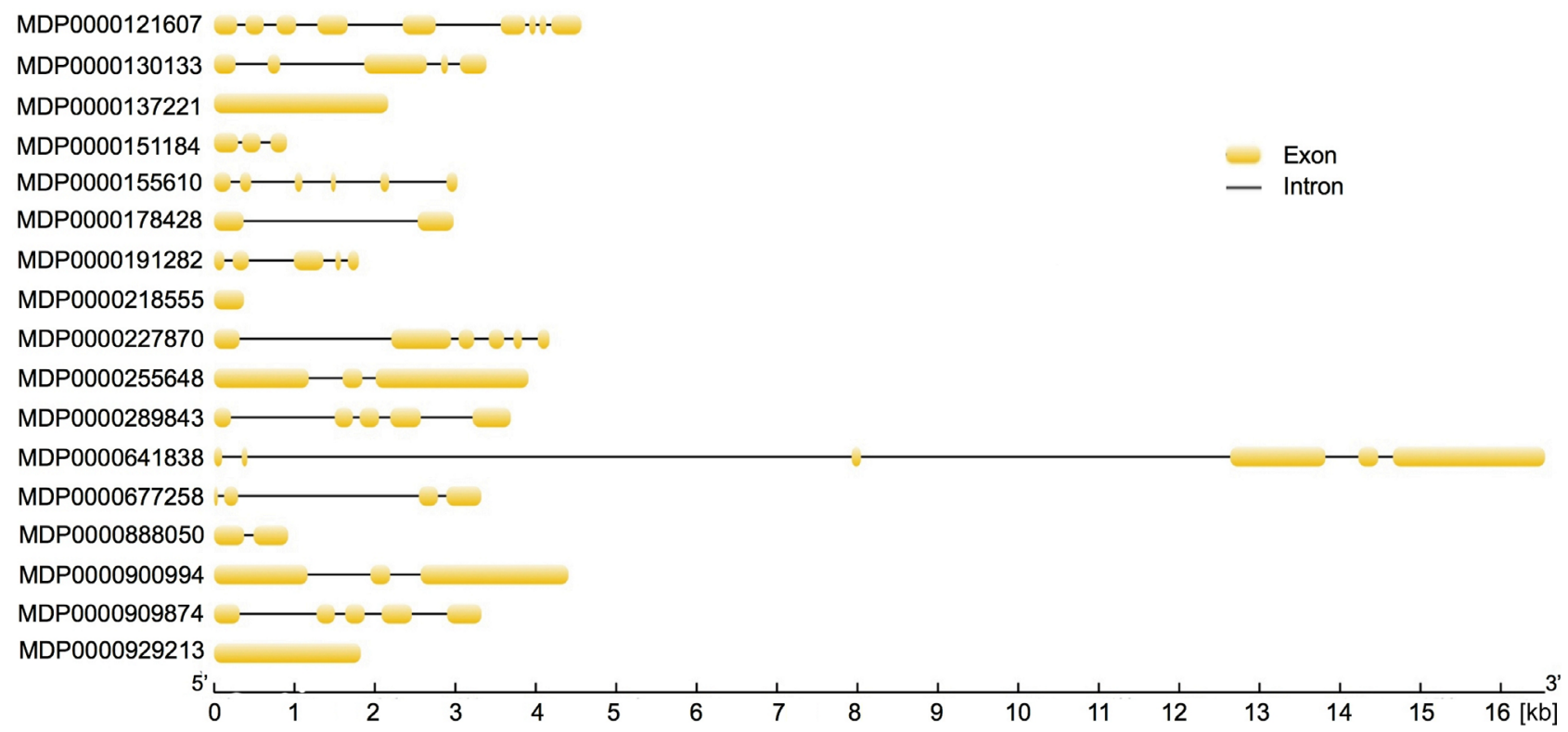

Fig. 2. The structure of apple strigolactones related genes. 
Brown 1992, Hollender and Dardick 2014). Some recent studies strongly suggested that columnar growth phenotype results from the up-regulated expression of $M d C o 31$, encoding proteins 2OGD or Downy Mildew Resistant 6 (Wolters et al. 2013, Otto et al. 2014, Okada et al. 2016). So far it has been unclear how the columnar phenotype could be generated by MdCo31. The phytohormones are believed to have a pivotal role in the regulation of the plant architecture (Ferguson and Beveridge 2009, Müller and Leyser 2011, Qi et al. 2011, Dayan et al. 2012, Cheng et al. 2013, Krost et al. 2013). The SLs are thought to act as a second messenger that works with auxin to maintain apical dominance (Ferguson and Beveridge 2009, Cheng et al. 2013, Hollender and Dardick 2014). Mutants in biosynthesis and signaling of SLs show a high degree of bud break and branching (Shinohara et al. 2013), which is similar to the phenotype of the columnar apple. The role of SLs has not been well studied in trees. In this study, the content of SLs was higher in columnar apple, indicating that SL could inhibit its lateral branching.

The SLs have tricyclic-lactone (ABC-ring) and methyl butenolide (D-ring), and they are connected through an enol ether bridge (Alder et al. 2012). Recently, the SLs biosynthetic pathway has been proposed, SLs might be synthesized via the carotenoid pathway (Matusova et al. 2005, Alder et al. 2012, Seto et al. 2014). The first branching genes cloned were $M A X$ genes in model plant Arabidopsis. MAX3 (CCD7) and MAX4 (CCD8) encode two $C C D$ which are targeted to the plastids (Domagalska and Leyser 2011, Harrison and Bugg 2014). The MAX1 belongs to the gene family encoding cytochrome $\mathrm{P}_{450}$, and these genes are involved in the biosynthesis of hormones (Lin et al. 2009). The MAX2 is the orthologous member of the F-box leucine-rich repeat protein family. The MAX1 has a role in signal transduction of the hormones (Ishikawa et al. 2005, Johnson
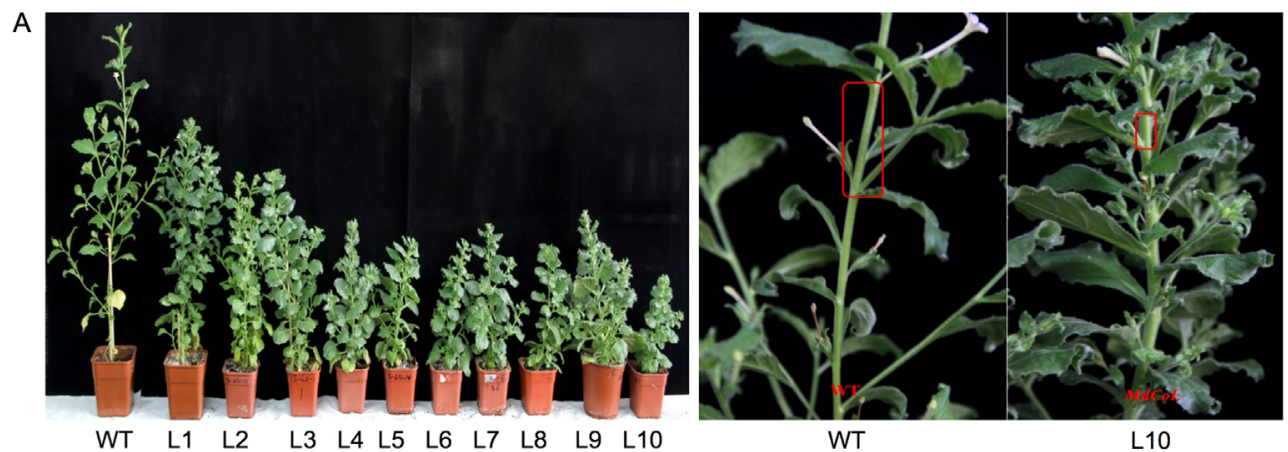

B
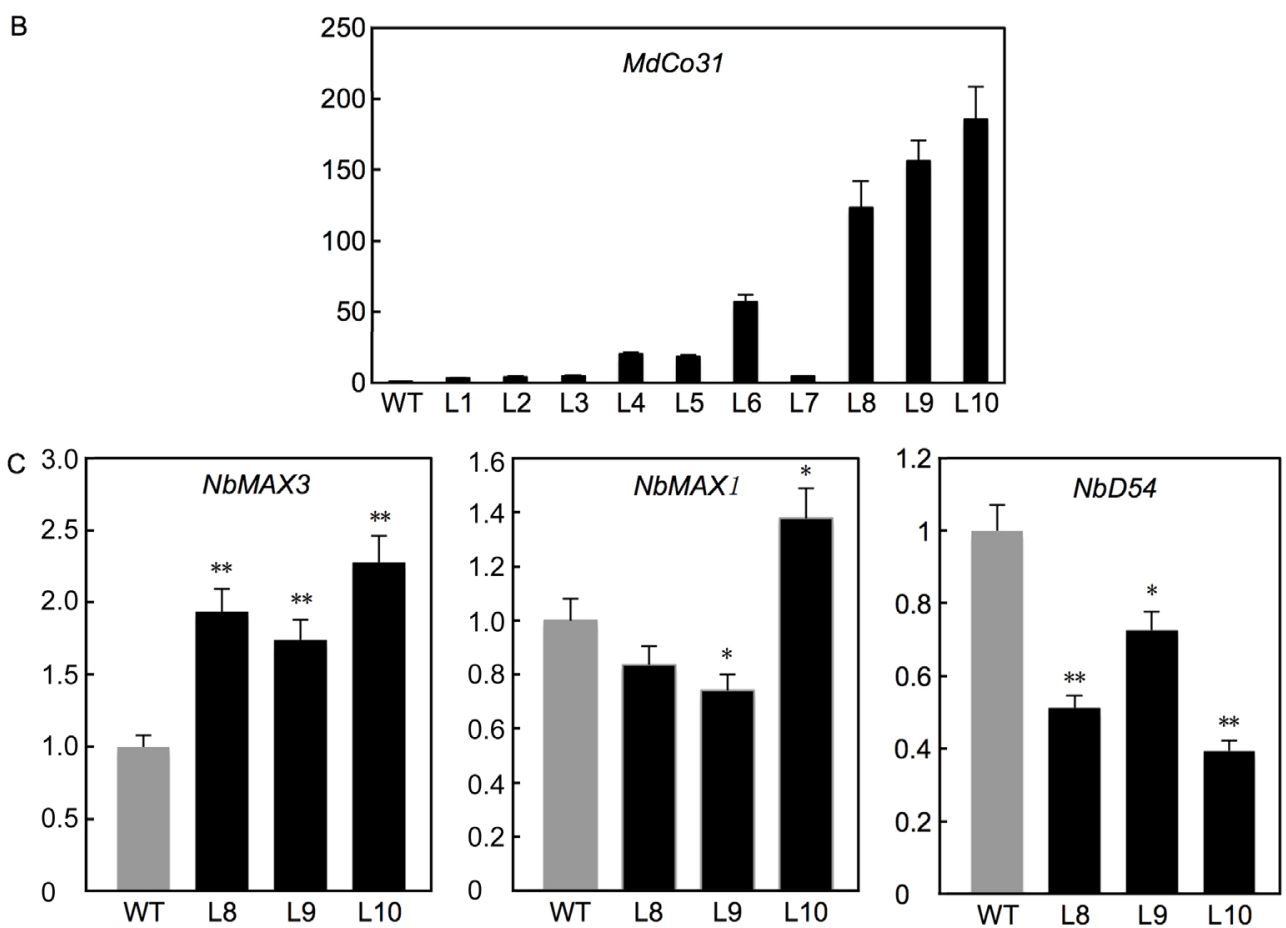

Fig. 3. Morphological differences in wild-type (WT) and transformed tobacco plants (L1 - L10; $A$ ). Reverse transcription quantitative PCR analysis of the $M d C o 31$ gene in WT and transgenic tobacco lines $(B)$. Expression analysis of genes related to strigolactones biosynthesis and signaling $(C)$. Means \pm SEs, $n=3, *, * *$ - significant differences at $P<0.01$ and $<0.001$, respectively, according to the Duncan's multiple range test. L8 - L10 - MdCo31 transgenic tobacco lines. 
Table 1. Comparison of some characteristics in 40-d-old wild-type (WT) and MdCo31 transgenic (L8, L9, and L10) tobacco plants. Means SEs, $n=30, * * *$ - significant differences at $P<0.01$ and $<0.001$, respectively according to the Duncan's multiple range test. SPAD - chlorophyll content.

\begin{tabular}{llllll}
\hline & Height $[\mathrm{cm}]$ & Internode length $[\mathrm{cm}]$ & Flower number & Branch number & SPAD \\
\hline WT & $46.08 \pm 1.63$ & $2.32 \pm 0.51$ & $43.2 \pm 9.2$ & $14.2 \pm 2.1$ & $44.13 \pm 1.4$ \\
L8 & $16.54 \pm 1.13^{* *}$ & $1.24 \pm 0.39^{*}$ & $44.8 \pm 8.5$ & $13.4 \pm 3.5$ & $48.57 \pm 0.9^{*}$ \\
L9 & $19.73 \pm 1.42^{* *}$ & $1.06 \pm 0.21^{* *}$ & $51.4 \pm 5.2^{*}$ & $11.9 \pm 1.9^{*}$ & $46.23 \pm 1.8^{*}$ \\
L10 & $18.01 \pm 0.82^{* *}$ & $0.92 \pm 0.25^{*}$ & $68.2 \pm 9.3^{*}$ & $16.7 \pm 5.4$ & $48.961 .1^{*}$ \\
\hline
\end{tabular}

et al. 2006, Lin et al. 2009, Al-Babili and Bouweester 2015). The DWARF14 (D14) encodes an $\alpha / \beta$ hydrolase, which interacts with strigolactones and MAX2 and is the possible receptor of strigolactones (Nakamura et al. 2013). The DWARF53 (D53) is the target protein of the D14-MAX2 complex and act as a repressor of SLs signaling pathway, which can abrogate SLs activity in promoting axillary bud growth (Zhou et al. 2013). The D27 encodes a protein ferritin, which is localized in the chloroplast and contains an enzyme functional region and is mainly expressed in vascular cells (Lin et al. 2009).

To better understand the function of SLs on the formation of column type characters, the members of major genes implicated in SLs biosynthesis and signal transduction were identified in the apple genome, and the expression profiles were characterized in columnar and standard apple trees. SLs, being proposed as branch inhibiting hormone (Shinohara et al. 2013, Hollender and Dardick 2014), are the carotenoid-derived compounds produced by action of $M A X 3$ and $M A X 4$. It is likely that SLs are mainly synthesized in roots (Kohlen et al. 2011). Here we confirmed that apple could synthesize the SLs, and interestingly they were likely synthesized in the buds. The content of SLs in buds and the number of SL biosynthesis related EST were analyzed. (Fig 1 Suppl., Table 2 Suppl.), which indicates that the synthesis of the SLs not only existed in the roots but also in the buds. The transcriptions of SLs biosynthesis related genes in the buds were higher than in the shoots (Fig. 3). Thus, we predicted that SLs could regulate the formation of columnar type characters in the buds. Seventeen SLs synthesis and signaling relevant genes were identified, of which six genes had striking differences in expression between columnar and standard apples throughout the different period of bud and shoot development (Fig. 1 Suppl.).

The MAX3 and MAX4 are critical for SLs biosynthesis in plants (Gomez-Roldan et al. 2008). The higher expressions of MdMAX3-1 and MdMAX4-4 in both buds and shoots of columnar apple suggest that transcript abundance of $M A X 3$ and MAX4 resulted in high SLs content (Fig. 1 Suppl.). The study of high-branching mutants in several species indicated that D27 might also be a key gene involved in the synthesis of SLs (Lin et al. 2009, Waters et al. 2012). Given the plastid localization of D27, it appears likely that this enzyme acts upstream of the endoplasmic reticulum-localized $M A X 1, M A X 3$, and MAX4 in the SL pathway (Lin et al. 2009, Al-Babili and Bouweester 2015). Among MdD27 genes examined,
MdD27-1 showed a high expression in columnar apple, whereas the expression of other three MdD27 genes fluctuated at similar levels between the buds and the shoots of columnar apple (Fig. 1 Suppl.). But, the relationship between the D27 gene and the regulated columnar type traits need further studies. The branched phenotypes of Arabidopsis $d 27$ are relatively mild compared with the phenotypes of other SL biosynthetic mutants (Lin et al. 2009, Smith and Waters 2012, Al-Babili and Bouweester 2015 ) indicating the presence of another 9 -cis- $\beta$-carotene source in these mutants. The MdMAX1-1 had a decreased expression in the buds and the shoots, which was consistent with MdMAX3-1 and MdMAX4-3 (Fig. 1 Suppl.). These results also add the evidences about the postulation that $M A X 1$ acts in a biosynthetic step downstream of $M A X 3$ and MAX4 (Booker et al. 2005, Al-Babili and Bouweester 2015). The maxl rootstock could restore a wild type branching pattern in $\max 3$ and $\max 4$ shoots,suggesting that MdMAX1 could regulate a columnar habit (Booker et al. 2005, Scaffidi et al. 2013, Seto et al. 2014). The D53, which is an inhibitor of the SLs signaling pathway, was recently elucidated in a rice mutant(Zhou et al. 2013). The MdD53-4 showed a lower expression in columnar apple (Fig. 1 Suppl.), which had a weak inhibitory effect on SLs signal transduction. In addition, the expression of $\mathrm{NbD} 53$ in transgenic tobacco was lower than in the wild type (Fig. 5). The MdD53 was likely to be central to SLs-mediated branch regulation.

The MdCo31 was a strongly dominant gene for regulation of columnar growth phenotype (Wolters et al. 2013, Otto et al. 2014, Okada et al. 2016). In our study, the higher expression in columnar apple and the heterotopic expression leading to the formation of tobacco columnar traits (Fig. 1, Fig. $3 A$ ) confirmed the role of MdCo31 in formation of columnar type. The expression of $\mathrm{NbMAXI}$ decreased in transgenic lines 8 and 9, whereas it increased in line 10. This result may indicate the $M d \operatorname{Co} 31$ is not a factor regulating the expression of MAX1. The transgenic tobacco plant exhibited an increased expression of NbMAX3 and a decreased expression of NbD53 (Fig. 3C). These results suggest that $M d C o 31$ could increase SLs content and weaken the inhibition of SLs signal transduction by increasing expression of $M A X 3$ and downregulating the transcription of D53 and then regulate the columnar character through SLs mediated manner.

As it is commonly found for other plant hormones, SLs biosynthesis and activity could be regulated by complex networks with other hormones. This is particularly true 
for auxin, abscisic acid, and brassinosteroids, which regulate SLs biosynthesis and are involved in most of the SL-regulated developmental processes (Lechat et al. 2012, Toh et al. 2012, Shinohara et al. 2013, Wang et al. 2013). The MdCo31 protein revealed the DIOX-N motif and the Fe(II)-dependent oxygenase domain. Members of the gene family containing these domains could catalyze the oxidation of organic substrates and were shown to be involved in the biosynthesis of hormones and flavonoids, and defense against downy mildew (Van Damme et al. 2008, Wolters et al. 2013, Kawai et al. 2014). Further study for better understanding SLs and MdCo31 regulations of the columnar habit, in particular, how MdCo31 and SLs interact each other, is scientifically interesting and also practically important for columnar habit management and utilization.

\section{References}

Arite, T., Iwata, H., Ohshima, K., Maekawa, M., Nakajima, M., Kojima, M., Sakakibara, H., Kyozuka, J.: DWARF10, an RMS1/MAX4/DAD1 ortholog, controls lateral bud outgrowth in rice. - Plant J. 51: 1019-1029, 2007.

Al-Babili, S., Bouwmeester, H.J.: Strigolactones, a novel carotenoid-derived plant hormone. - Annu. Rev. Plant Biol. 66: 161-186, 2015

Alder, A., Jami, M., Marzorati, M., Bruno, M., Vermathen, M., Bigler, P., Ghisla, S., Bouwmeester, H., Beyer, P., AI-Babili, S.: The path from $\beta$-carotene to carlactone, a strigolactonelike plant hormone. - Science 335: 1348-1351, 2012.

Arite, T., Umehara, M., Ishikawa, S., Hanada, A., Maekawa, M., Yamaguchi, S., Kyozuka, J.: d14, a strigolactone-insensitive mutant of rice, shows an accelerated outgrowth of tillers. Plant Cell Physiol. 50: 1416-1424, 2009.

Bai, T., Zhu, Y., Fernandez-Fernandez, F., Keulemans, J., Brown, $\mathrm{S}$., $\mathrm{Xu}, \mathrm{K}$.: Fine genetic mapping of the Co locus controlling columnar growth habit in apple. - Mol. Genet. Genomics 287: 437-450, 2012.

Baldi, P., Wolters, P.J., Komjanc, M., Viola, R., Velasco, R., Salvi, S.: Genetic and physical characterization of the locus controlling columnar habit in apple (Malus $\times$ domestica Borkh.). - Mol. Breed. 31: 429-440, 2013.

Beveridge, C.A.: Long-distance signaling and a mutational analysis of branching in pea. - Plant Growth Regul. 32: 193203, 2000.

Booker, J., Auldridge, M., Wills, S., McCarty, D., Klee, H., Leyser, O.: MAX3/CCD7 is carotenoid cleavage dioxygenase required for the synthesis of a novel plant signaling molecule. - Curr. Biol. 14: 1232-1238, 2004.

Booker, J., Sieberer, T., Wright, W., Williamson, L., Willett, B., Stirnberg, P., Turncull, C., Srinivasan, M., Goddard, P., Leyser, O.: $M A X 1$ encodes a cytochrome $\mathrm{P}_{450}$ family member that acts downstream of $M A X 3 / 4$ to produce a carotenoidderived branch inhibiting hormone. - Dev. Cells 8: 443-449, 2015.

Cheng, X., Ruyter-Spira, C., Bouwmeester, H.: The interaction between strigolactones and other plant hormones in the regulation of plant development. - Front. Plant Sci. 4: 199, 2013.

Dayan, J., Voronin, N., Gong, F., Sun, T.P., Hedden, P., Fromm, H., Aloni, R.: Leaf-induced gibberellin signaling is essential for internode elongation, cambial activity, and fiber differentiation in tobacco stems. - Plant Cell 24: 66-79, 2012.
Domagalska, M.A., Leyser, O.: Signal integration in the control of shoot branching. - Nat. Rev. mol. cell. Biol. 12: 211-221, 2012.

Drummond, R.S.M., Martínez-Sánchez, N.M., Janssen, B.J., Templeton, K.R., Simons, J.L., Sakuntala, B.D.Q., Karunairetnam, S., Snowden, K.C.: Petunia hybrida CAROTENOID CLEAVAGE DIOXYGENASE7 is involved in the production of negative and positive branching signals in petunia. - Plant Physiol. 151:1867-1877, 2009.

Foo, E., Reid, J.B.: Strigolactones: new physiological roles for an ancient signal. - J. Plant Growth Regul. 32: 429-442, 2013.

Ferguson, B.J., Beveridge, C.A.: Roles for auxin, cytokinin, and strigolactone in regulating shoot branching. - Plant Physiol. 149: 1929-1944, 2009.

Gomez-Roldan, V., Fermas, S., Brewer, P.B., Puech-Pagès, V., Dun, E.A., Pillot, J.P., Letisse, F., Matusova, R., Danoun, S., Portais, J.C., Bouwmeester, H., Bècard, G., Beveridge, C.A., Rameau, C., Rochange, S.F.: Strigolactone inhibition of shoot branching. - Nature 455: 189-194, 2008.

Hamiaux, C., Drummond, R.S., Janssen, B.J., Ledger, S.E., Cooney, J.M., Newcomb, R.D., Snowden, K.C.: DAD2 is an $\alpha / \beta$ hydrolase likely to be involved in the perception of the plant branching hormone, strigolactone. - Curr. Biol. 22: 2032-2036, 2012.

Harrison, P.J., Bugg, T.D.H.: Enzymology of the carotenoid cleavage dioxygenases: reaction mechanisms, inhibition and biochemical roles. - Arch. Biochem. Biophys. 544: 105-111, 2014.

Hollender, C.A., Dardick, C.: Molecular basis of angiosperm tree architecture. - New Phytol. 206: 541-556, 2014.

Ishikawa, S., Maekawa, M., Arite, T., Onishi, K., Takamure, I., Kyozuka, J.: Suppression of tiller bud activity in tillering dwarf mutants of rice. - Plant Cell physiol. 46: 79-86. 2005.

Jiang, L., Liu, X., Sheng, S.G., Liu, H.H., Chen, F.L., Wang, L., Meng, X.B., Liu, G.F., Yu, H., Yuan, Y.D., Yi, W., Zhao, L.H., Ma, H.L., He, Y.Z., Wu, Z.S., Karsten, M., Qian, Q., Xu, E.H., Wang, Y.H., Li, J.Y.: DWARF53, acts as repressor of strigolactone signaling in rice. - Nature 504: 401-405, 2013.

Johnson, X., Brcich, T., Dun, E.A., Gousso,t M., Haurogne, K., Beveridge, C.A., Rameau, C.: Branching genes are conserved across species. Genes controlling a novel signal in pea are coregulated by other long-distance signals. - Plant Physiol. 142: 1014-1026, 2006.

Kawai, Y., One, E., Mizutani, M.: Evolution and diversity of the 2-oxoglutarate-dependent diosygenase superfamily in plants. - Plant J. 78: 328-343, 2014.

Kelsey, D.F., Brown, S.K.: 'McIntosh Wijcik': a columnar mutation of 'McIntosh' apple proving useful in physiology and breeding research. - Fruit Varieties J. 46: 83-87, 1992.

Kim, H.I., Xie, X., Kim, H.S., Chun, J.C., Yoneyama, K., Nomura, T., Takeuchi, Y., Yoneyama, K. Structure-activity relationship of naturally occurring strigolactones in Orobanche minor seed germination stimulation. - J. Pest. Sci. 35: 344-347, 2000.

Kohlen, W., Charnikhova, T., Liu, Q., Bours, R., Domagalska, M.A., Beguerie, S., Ruyter-Spira, C.: Strigolactones are transported through the xylem and play a key role in shoot architectural response to phosphate deficiency in nonarbuscular mycorrhizal host Arabidopsis. -Plant Physiol. 155: 974-987, 2011.

Kretzschmar, T., Kohlen, W., Sasse, J., Borghi, L., Schlegel, M., Bachelier, J.B., Reinhardt, D., Bours, R., Bouwmeester, H.J., Martinoia, E.: A petunia ABC protein controls strigolactonedependent symbiotic signaling and branching. - Nature 483: 341-344, 2012.

Krost, C., Petersen, R., Lokan, S., Brauksiepe, B., Braun, P., Schmidt, E.R.: Evaluation of the hormonal state of columnar 
apple trees (Malus $\times$ domestica) based on high throughput gene expression studies. - Plant mol. Biol. 81: 211-220, 2013.

Lazar, G., Goodman, H.M.: MAX1, a regulator of the flavonoid pathway, controls vegetative axillary bud outgrowth in Arabidopsis. - Proc. nat. Acad. Sci. USA 10: 472-476, 2006.

Lechar, M.M., Pouvreau, J.B., Peron, T., Gauthier, M., Montiel, G., Veronesi, C., Todoroki, Y., Le Bizec, B., Monteau, F., Macherel, D., Simier, P., Thoiron, S., Delavault, P.: PrCYP707A1, an ABA catabolic gene, is a key component of Phelipanche ramose seed germination in response to the strigolactone analogue GR24. - J. exp. Bot. 63: 5311-5322, 2012.

Li, T., Sun, J., Bi, Y., Peng, Z. Overexpression of an MYB-related gene FvMYB1 from Fraxinus velutina increase tolerance to salt stress in transgenic tobacco. - J. Plant Growth Regul. 35: 632-645, 2016.

Lin, H., Wang, R., Qian, Q., Yan, M., Meng, X., Fu, Z., Yan, C., Jiang, B., Su, Z., Li, J., Wang, Y.: DAWRF27, an iron-containing protein required for the biosynthesis of strigolactones, regulates rice tiller bud outgrowth. - Plant Cell 21: 1512-1525, 2009.

Matusova, R., Rani, K., Verstappen, F.W., Franssen, M.C., Beale, M.H., Bouwmeester, H.J. The strigolactone germination stimulants of the plant-parasitic Striga and Orobanche spp. are derived from the carotenoid pathway. - Plant Physiol. 139: 920-934, 2005.

Moriya, S., Iwanami, H., Kotoda, N., Takahashi, S., Yamamoto, T., Abe, K.: Development of a marker-assisted selection system for columnar growth habit in apple breeding. - J. jap. Soc. hort. Sci. 78: 279-287, 2009.

Moriya, S., Okada, K., Haji, T., Yamamoto, T., Abe, K.: Fine mapping of $\mathrm{Co}$, a gene controlling columnar growth habit located on apple (Malus $\times$ domestic Borkh.) linkage group 10 . - Plant Breed. 131: 641-647, 2012.

Müller, D., Leyser, O.: Auxin, cytokinin and the control of shoot branching. - Ann. Bot. 107: 1203-1212, 2011.

Nakamura, H., Xue, Y.L., Miyakawa, T., Hou, F., Qin, H.M., Fukui, K., Shi, X., Ito, E., Ito, S., Park, S.H., Miyauchi, Y., Asano, A., Totsuka, N., Ueda, T., Tanokura, M., Asami, T. Molecular mechanism of strigolactone perception by DWARF14. - Nat. Commun. 4: 2613, 2013.

Okada, K., Wada, M., Moriya, S., Katayose, Y., Fujisawa, H., Wu, J., Kanamori, H., Kurita, K., Sasaki, H., Fujii, H., Terakami, S., Iwanami, H., Yamamoto, T., Abe, K.: Expression of a putative dioxygenase gene adjacent to an insertion mutation is involved in the short internodes of columnar apples (Malus $\times$ domestica). - J. Plant Res. 129: 1109-1126, 2016.

Otto, D., Petersen, R., Brauksiepe, B., Braun, P., Schmidt, E.R.: The columnar mutation ('Co gene') of apple (Malus $\times$ domestica) is associated with an integration of a Gypsy-like retrotransposon. - Mol. Breed. 33: 863-880, 2014.

Petersen, R., Djozgic, H., Rieger, B., Rapp, S., Schmidt, E.R. Columnar apple primary roots share some features of the columnar specific gene expression profile of aerial plant parts as evidenced by RNA-Seq analysis. - BMC Plant Biol. 15: 34, 2015.

Petersen, R., Krost, C.: Tracing a key player in the regulation of plant architecture: the columnar growth habit of apple trees (Malus $\times$ domestica). - Planta 238: 1-22, 2013.

Qi, W., Sun, F., Wang, Q., Chen, M., Huang, Y., Feng, Y.Q., Luo, X., Yang, J.: Rice ethylene-response AP2/ERF factor $O S E A T B$ restricts internode elongation by down-regulating a gibberellin biosynthetic gene. - Plant Physiol. 157: 216-228, 2011.

Scaffidi, A., Waters, M.T., Ghisalberti, E.L., Dixon, K.W., Flematti, G.R., Smith, S.M.: Carlactone-independent seedling morphogenesis in Arabidopsis. - Plant J. 76: 1-9, 2013.

Shinohara, N., Taylor, C., Leyser, O.: Strigolactone can promote or inhibit shoot branching by triggering rapid depletion of the auxin efflux protein PIN1 from the plasma membrane. - PLoS Biol. 11: e1001474, 2013.

Smith, S.M., Waters, M.T.: Strigolactones: destruction-dependent perception? - Curr. Biol. 22: R924-R927, 2012.

Snowden, K.C., Simkin, A.J., Janssen, B.J., Templeton, K.R., Loucas, H.M., Smons, J.L., Karunairetnam, S., Gleave, A.P., Clark, D.G., Klee, H.J.: The decreased apical dominance1/ Petunia hybrid CAROTENOID CLEAVAGE DIOXYGENASE8 gene affects branch production and plays a role in leaf senescence, root growth, and flower development. - Plant Cell 17: 746-759, 2005.

Seto, Y., Sado, A., Asami, K., Hanada, A., Umehara, M., Akiyama, K., Yamaguchi, S.: Carlactone is an endogenous biosynthetic precursor for strigolactones. - Proc. nat. Acad. Sci. 111: 1640-1645, 2014.

Sorefan, K., Booker, J., Haurogné, K., Goussot, M., Bainbridge, K., Foo, E., Chatfield, S., Ward, S., Beveridge, C., Rameau, C., Leyser, O.: MAX4 and RMS1 are orthologous dioxygenaselike genes that regulate shoot branching in Arabidopsis and pea. - Genes Dev. 17: 1469-1474, 2003.

Stirnberg, P., Furner, I.J., Ottoline, L.H. MAX2 participates in an SCF complex which acts locally at the node to suppress shoot branching. - Plant J. 50: 80-94, 2007.

Stirnberg, P., Van de Sande, K., Leyser, H.M.: MAX1 and MAX2 control shoot lateral branching in Arabidopsis. - Development 129: 1131-1141, 2002.

Toh, S., Kamiya, Y., Kawakami, N., Nambara, E., McCourt, P., Tsuchiya, Y.: Thermoinhibiton uncovers a role for strigolactones in Arabidopsis seed germination. - Plant Cell physiol. 53: 107-117, 2012.

Umehara, M., Hanada, A., Yoshida, S., Akiyama, K., Arite, T., Takeda-Kamiya, N., Magome, H., Kamiya, Y., Shirasu, K., Yoneyama, K., Kyozuka, J., Yamaguchi, S. Inhibition of shoot branching by new terpenoid plant hormones. - Nature 455: 195-200, 2008.

Van Damme, M., Huibers, R.P., Elberse, J., Van den Ackerveken, G. Arabidopsis DMR6 encodes a putative 2OG-Fe(II) oxygenase that is defense-associated but required for susceptibility to downy mildew. - Plant J. 54: 785-793, 2008.

Wang, Y., Sun, S., Zhu, W., Jia, K., Yang, H., Wang, X.: Strigolactone/MAX2-induced degradation of brassinosteroid transcriptional effector BES1 regulates shoot branching. Dev. Cells 27: 681-688, 2013.

Waters, M.T., Brewer, P.B., Bussell, J.D., Smith, S.M., Beveridge, C.A.: The Arabidopsis ortholog of rice DWARF27 acts upstream of $M A X 1$ in the control of plant development by strigolactones. - Plant Physiol. 159: 1073-1085, 2012.

Wolters, P.J., Schouten, H.J., Velasco, R., Si-Ammour, A., Baldi, P.: Evidence for regulation of columnar habit in apple by a putative 2OG-Fe(II) oxygenase. - New Phytol. 200: 993-999, 2013.

Yue, Z., Liu, H., Ma, F.: The Malus carotenoid cleavage dioxygenase 7 is involved in stress response and regulated by basic pentacysteine 1. - Sci. Hort. 192: 264-270, 2015.

Zhang, W., Dong, C., Zhang, Y., Zhu, J., Dai, H., Bai, S.: An apple cyclic nucleotide-gated ion channel gene highly responsive to Botryosphaeria dothidea infection enhances the susceptibility of Nicotiana benthamiana to bacterial and fungal pathogens. - Plant Sci. 269: 94-105, 2018.

Zhang, Y., Zhu, J., Dai, Y.: Characterization of transcriptional differences between columnar and standard apple trees using RNA-seq. - Plant mol. Biol. Rep. 30: 957-965, 2012.

Zhou, F., Lin, Q., Zhu, L., Ren, Y., Zhou, K., Shabek, N., Wu, F., 
Mao, H., Dong, W., Gan, L., Ma, W., Gao, H., Chen, J., Yang, C., Wang, D., Tan, J., Zhang, X., Guo, X., Wang, J., Jiang, L., Liu, X., Chen, W., Chu, J., Yan, C., Ueno, K., Ito, S., Asami, T., Cheng, Z., Wang, J., Lei, C., Zhai, H., Wu, C., Wang, H., Zheng, N., Wan, J.: D14-SCF ${ }^{\mathrm{B}}$-dependent degradation of D53 regulates strigolactone signaling. - Nature 504: 406-410,
2013.

Zou, J., Zhang, S., Zhang, W., Li, G., Chen, Z., Zhai, W., Zhao, X., Pan, X., Xie, Q., Zhou, L.: The rice HIGH-TILLERING $D W A R F 1$ encoding an ortholog of Arabidopsis MAX3 is required for negative regulation of the outgrowth of axillary buds. - Plant J. 48: 687-698, 2006. 